\title{
Modified gypsum binder
}

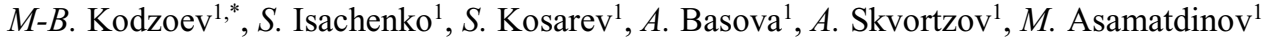 \\ and $A$. Zhukov ${ }^{1}$
}

${ }^{1}$ Moscow State University of Civil Engineering, Yaroslavskoe shosse, 26, Moscow, 129337, Russia

\begin{abstract}
Gypsum-based binder modified by clay has properties close to the gypsum binder and can be used as plaster formulations or mortars. There are several reasons and chief among them is the lack of scientific based theory of formation and hardening properties of gypsum-based binder modified by clay without additives and that modified by additives. One of the classic ways of studying the mechanism of hydration of gypsum binders is the analysis of the heat liberation: hydration heat of the binder. With the thermos method of determining the heat liberation the ambient temperature is constant and the temperature of the sample which was at the beginning of the experiment changes as a result of the released heat of hydration of the gypsum; heat exchange between sample and the environment. Heat transfer is minimized through the use of thermos technology and effective insulation. The article presents the results of studying the dynamics of heat liberation during hydration of gypsum-based binder modified by clay without additives, with addition of superplasticizer and with the addition of setting retarder. Results in all cases are satisfactory. The highest degree of hydration evaluated by kinetics of heat liberation from a binder is with the addition of the superplasticizer. Application of setting retarder somewhat reduces the maximum degree of hydration and increases the hydration time. The degree of hydration of the binder with the addition of $\mathrm{C} 3$ additive and retarder is observed to be higher than that of gypsum-based binder modified by clay without additives. The studies confirm the possibility of using gypsum-based binder modified by clay in the composition of dry plaster mixtures for interior decoration works in premises.
\end{abstract}

\section{Introduction}

Gypsum-based binder modified by clay is a natural material of sedimentary origin which is widespread within the Russian Federation and in Central Asia. By its properties it is close to gypsum and can be used as its substitute in plaster and mortar [1-4]. Let us call gypsum-based binder modified by clay a clay-gypsum.

In Central Asia clay-gypsum plaster finished with elegant ornamental or pictorial carvings was very popular decorative tool not only in the mosques and palaces but also in people's houses. From the middle of the XV century it was applied on the walls of paintings called "kundal". A slight relief pattern of red clay with admixture of plant glue and gypsum

\footnotetext{
*Corresponding author: basir731@yandex.ru
} 
was applied on the prepared stucco wall surface. Relief patterns were covered with gilding and the background was painted blue and decorated with fine floral patterns [5-8].

The raw material for the production of plaster was gypsum with natural clay

admixture, which is widely spread in Central Asia - clay-gypsum, also called "ganch" (ganch - local name of clay-gypsum in Central Asia), which is light

greyish or yellowish hue and now is widely used. Besides gypsum and clay "ganch" contains some silica and carbonate. Ganch from Uzbekistan for example contains up to 25 $\%$ clay and sand and up to $4 \%$ of carbonates and that from Turkmenistan (Ashkhabadsk deposit) $37-61 \%$ gypsum. Ganch usually occurs at a depth of 5-10 m and sometimes closer to the surface and surface exits (inferior quality) and is quarried $[9,10]$.

The water resistance and durability of ancient ganch stucco solution is seen in brick and stone structures with continuous exposure to water. An example is the arch bridge in the XIV century through Murghab (Turkmenistan) which served until its dismantling at the end of the XIX century and bathhouse in XVI century which is still in use in Bukhara today.

Formation of hardening hydration structures of clay-gypsum binder in contact with water is the basis of the hardening of mineral binders. For clay-gypsum fired at a temperature of $250{ }^{\circ} \mathrm{C}$ the main structural element is a semi-liquid gypsum $\beta$-CaSO4 $2 \mathrm{H} 2 \mathrm{O}$. As with pure gypsum, which is dehydrated at the temperature up to $180{ }^{\circ} \mathrm{C}$, hardening processes of clay-gypsum binder is determined by conditions of reaction.

$\beta-\mathrm{CaSO} 4 \cdot 0.5 \mathrm{H} 2 \mathrm{O}+1.5 \mathrm{H} 2 \mathrm{O}=\mathrm{CaSO} 4 \cdot 2 \mathrm{H} 2 \mathrm{O}$

This process provides us with a general model to determine the nature of clay-gypsum hardening. Research by Le Chatelier. Mihaelises. A. A Baikov and others who advanced different hypotheses are classic representations [11, 12]. V. B. Ratinov studied and presented the basic laws of formation of crystallization of hardening structures.

Products from clay-gypsum thermal decomposition representing a substance with the same chemical nature as calcium sulphate but with a different rate of dissolution present an interesting research area of the role of these processes in the bond structure formation. The research carried out by us in the NRU MGSU measured the hydration kinetics of the claygypsum binder from Hodzhakulsk field (Republic of Karakalpakstan).

\section{Materials and methods}

Determination of heat of clay-gypsum hydration. Under thermos method for determining heat liberation the ambient temperature must be constant. The temperature of the sample which is the same at the beginning of the experiment changes spontaneously as a result of occurrence of two processes: heat liberation during gypsum hydration and heat exchange between the sample and the medium.

The first process leads to temperature rise, the second - in its drop. The final result depends on which is the greater: rate of heat liberation or rate of heat loss in the thermal environment. The method made the assumption that the sample temperature is the same at all points of its volume. In fact the temperature decreases from the center to the periphery of the sample. To level the sample temperature there is the need to create a high thermal resistance between the sample and the environment which will be localized in essentially the entire temperature drop.

The highest thermal resistance has vacuum flask (Dewar flask), which is a glass flask with double walls between which a vacuum is created. The absence of substance between the walls virtually eliminates heat transfer by convection and conduction but there remains a third way, a radiation. To reduce radiation flask walls are made like mirror - by coating with silver. This metal has a very high reflectance. In the simplest test scheme the calorimeter test medium is ambient air. In this manner, the temperature and heat exchange coefficient (heat transfer) between the thermos and the medium should be constant. The 
heat transfer index depends on the speed of air circulation of the thermos walls. It has the lowest value if the air is still. Characteristic of clay-gypsum binder is the heat liberation value

$$
\mathrm{q}=\mathrm{Q} / \mathrm{mg}
$$

It is convenient to calculate in a table. According to the results of the calculations we plot the relationship

$$
\mathrm{Q}=\mathrm{f}(\tau)
$$

Hydration kinetics was studied by thermocalorimetry. Digital thermometer TEN-5 produced in Russia with measuring working range of $100 \mathrm{~mm}$ was used during the test. When using the thermos method of determining heat liberation the ambient temperature must be constant. The room temperature (in the laboratory) was $\operatorname{tr}=25.6^{\circ} \mathrm{C}$ with daily variation not exceeding $\pm 1.5^{\circ} \mathrm{C}$. During the test period windows and doors remained close so $\operatorname{tr}=25.6^{\circ} \mathrm{C}=$ const. Before conducting the test the water was held in a separate container in the room for 3 days.

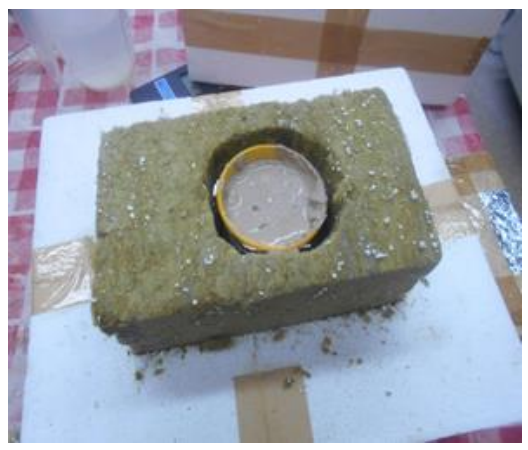

Fig 1. Installation of weighing bottle with clay-gypsum into mineral wool insulation

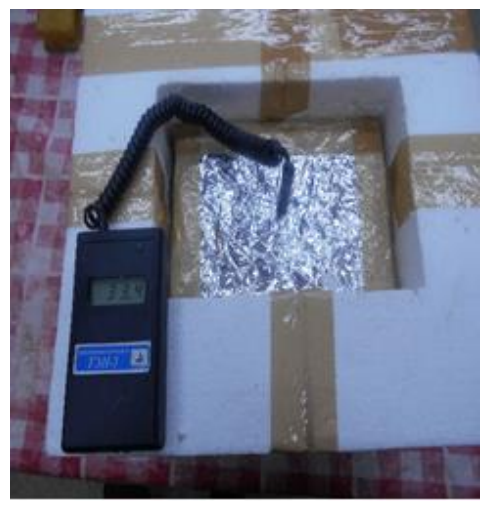

Fig 2. Assembled device (external thermal insulation of polystyrene foam with foil)

To avoid heat transfer through the walls between the sample and the wall there was a space up to $1 \mathrm{~cm}$. To reduce the radiation through the wall the container was wrapped in a silver foil. There was a distance of $1 \mathrm{~cm}$ between the vessel and the thermos lid. Hydration kinetics study allows establishing relation between the phase composition of the binder, features of its hydration and kinetics of formation, strength of hydration bond structures of hardening, which arise on the ground thereof. 


\section{Results and discussion}

Kinetics of the temperature rise for pure clay-gypsum, for clay-gypsum with $1 \% \mathrm{C}-3$ additive, and for clay-gypsum with $1 \% \mathrm{C}-3$ additive and $0.06 \%$ setting retarder was studied. Full-scale test results are shown on Fig. 2. Results of testing clay-gypsum without additives (Fig. 2a. Tab. 1) show that the temperature of the binder rises to $49.1{ }^{\circ} \mathrm{C}$ in 49 minutes and remains such from 4 to 52 minutes, and drops gradually from $49.1{ }^{\circ} \mathrm{C}$ to a constant temperature in 250 minutes. Under Dewar's method plaster test takes 1 hour, but cooling mode was also registered during our test.
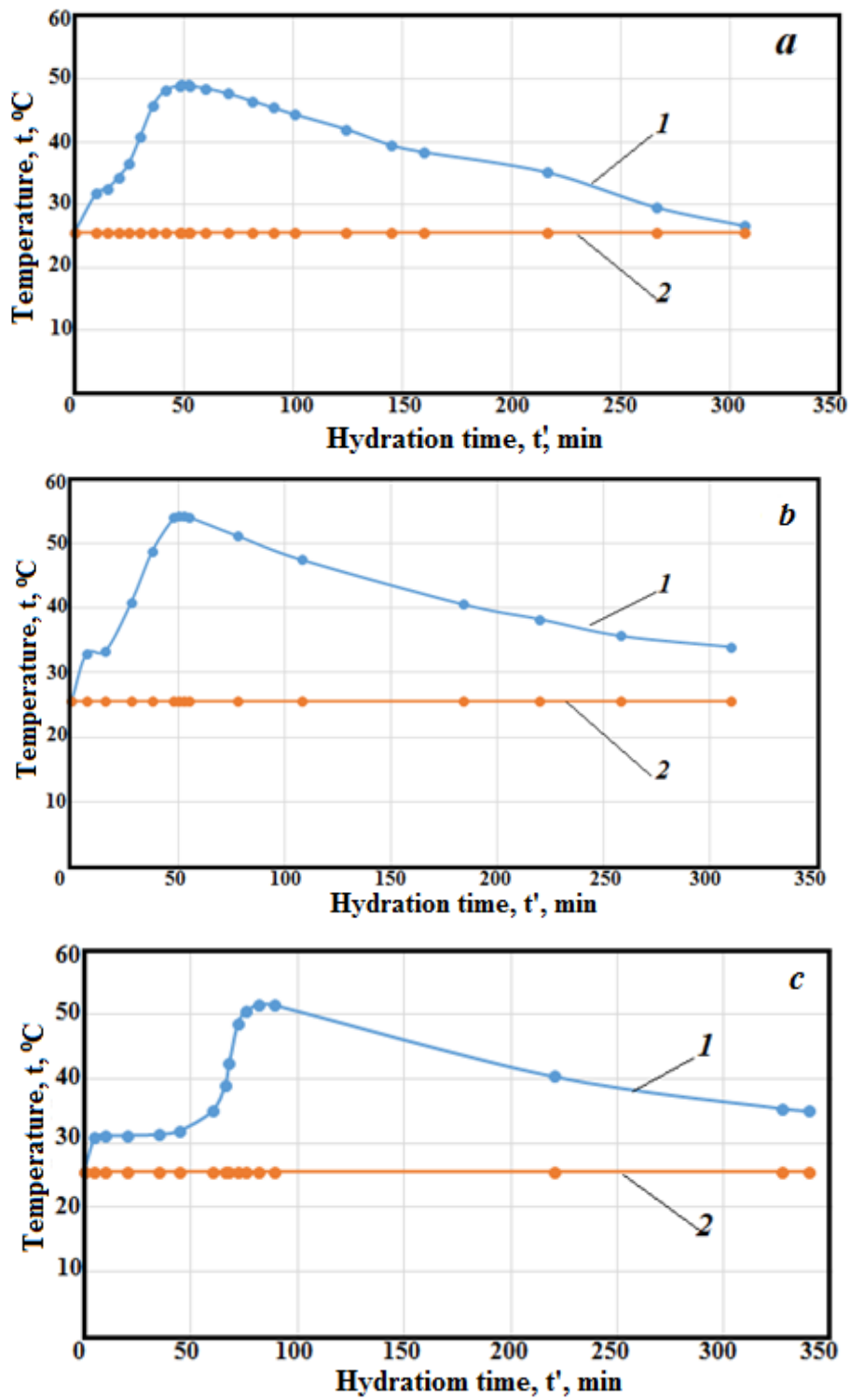

Fig. 3. Kinetics of temperature change during testing: a - clay-gypsum binder without additives; $b$ clay-gypsum binder with an additive of $1 \% \mathrm{C}-3$; c - clay-gypsum binder with the addition of $1 \% \mathrm{C}-3$ and $0.06 \%$ retarder; 1 - temperature of clay-gypsum binder; 2 - ambient temperature. 
With the addition of the $\mathrm{C}-3$ temperature rises on minute 50 to $54.2{ }^{\circ} \mathrm{C}$ and remains such for 4 minutes until the end of minute 53 (Fig. 2b. Tab. 1)). At the end of the test on minute 310 the temperature was $34^{\circ} \mathrm{C}$.

With the addition of the $\mathrm{C}-3$ and setting retarder peak hydration temperature was reached at minute 82 and remained such for 7 minutes (Fig. 2c. Tab. 1). The test ended at 340th minute with a temperature of $34^{\circ} \mathrm{C}$.

The kinetics of heat liberation of gypsum-containing mixtures is calculated on the basis of the temperature difference determined by thermometers and the additive heat capacity of the mixture. The heat liberation of the mixture (q. $\mathrm{kJ} / \mathrm{kg}$ ) is calculated. Taking into account all factors, the additive heat capacity of the mixture is taken equal to $21.25 \mathrm{~kJ} /(\mathrm{kg} \cdot \mathrm{oC})$. The results of the calculation are presented in Table. 1. and their graphical interpretation in Fig. 3.

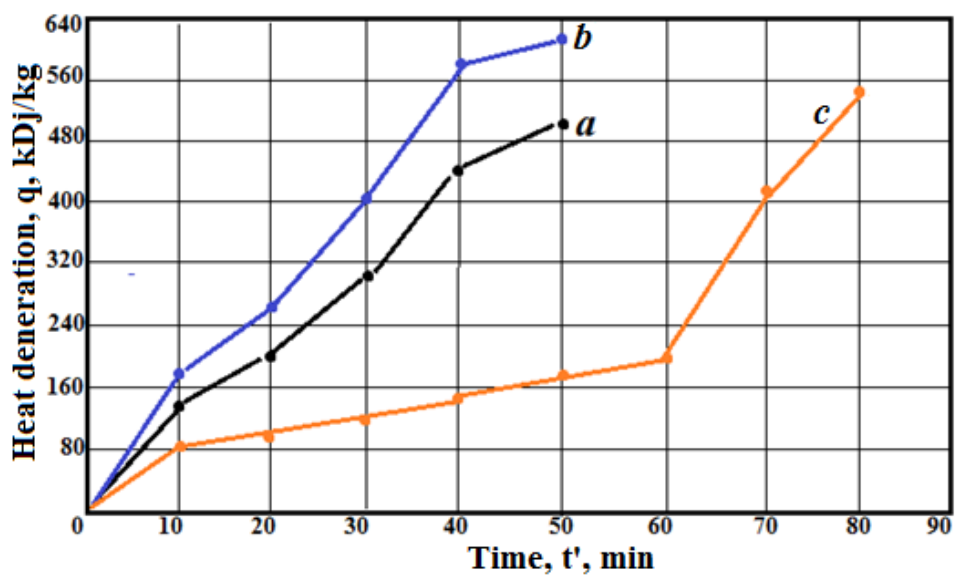

Fig. 4. Heat liberation of clay-gypsum binder with time: a - clay-gypsum binder without additives; b clay-gypsum binder with $1 \% \mathrm{C}-3$ additive; $\mathrm{c}$ - clay-gypsum binder with the addition of $1 \% \mathrm{C}-3$ and $0.06 \%$ retarder.

Table 1. Temperature and heat liberation of the clay-gypsum binder (room temperature. $t_{0}=25.6{ }^{\circ} \mathrm{C}$ )

\begin{tabular}{|c|c|c|c|c|c|c|c|c|c|}
\hline \multirow{3}{*}{$\begin{array}{l}. \Xi \\
\Xi \\
\dot{\Xi} \\
\Xi \\
\boxminus\end{array}$} & \multicolumn{9}{|c|}{ Clay-Gypsum Binder } \\
\hline & \multicolumn{3}{|c|}{ Without additives } & \multicolumn{3}{|c|}{ With $1 \% \mathrm{C}-3$ additive } & \multicolumn{3}{|c|}{$\begin{array}{l}\text { With } 1 \% \mathrm{C}-3 \text { additive and } \\
0.06 \% \text { retarder }\end{array}$} \\
\hline & $\begin{array}{l}\text { Tempe } \\
\text { rature. } \\
t_{x} \cdot{ }^{\circ} \mathrm{C}\end{array}$ & $\begin{array}{l}\text { Heat } \\
\text { liberation. } \\
\text { q. kJ / kg }\end{array}$ & $\begin{array}{l}\text { Degree } \\
\text { of } \\
\text { hydration } \\
\alpha . \%\end{array}$ & $\begin{array}{l}\text { Tempe } \\
\text { rature. } \\
t_{x} .{ }^{\circ} \mathrm{C}\end{array}$ & $\begin{array}{l}\text { Heat } \\
\text { liberati } \\
\text { on. q. } \\
\mathrm{kJ} / \mathrm{kg}\end{array}$ & $\begin{array}{l}\text { Degree } \\
\text { of } \\
\text { hydration } \\
\alpha . \%\end{array}$ & $\begin{array}{l}\text { Tempe } \\
\text { rature. } \\
t_{x} .{ }^{\circ} \mathrm{C}\end{array}$ & $\begin{array}{c}\text { Heat } \\
\text { liberatio } \\
\text { n. q. kJ/ } \\
\text { kg }\end{array}$ & $\begin{array}{l}\text { Degree } \\
\text { of } \\
\text { hydrati } \\
\text { on } \alpha . \\
\%\end{array}$ \\
\hline & 25.6 & ( & 0 & 25.6 & 0 & 0 & 25.6 & 0 & 0 \\
\hline 10 & 31.9 & 127.5 & 21 & 33.2 & 170.0 & 28 & 31.2 & 85.0 & 14 \\
\hline 20 & 34.4 & 191.2 & 31 & 37.9 & 255.0 & 41 & 31.2 & 106.3 & 17 \\
\hline 30 & 40.8 & 318.8 & 52 & 44.2 & 403.8 & 66 & 31.3 & 127.5 & 21 \\
\hline 40 & 48.0 & 467.5 & 76 & 54.0 & 595.0 & 97 & 31.8 & 148.8 & 24 \\
\hline 50 & 49.1 & 488.8 & 79 & 54.2 & 616.3 & 100 & 33.4 & 170.0 & 28 \\
\hline 60 & & & & & & - & 35.0 & 191.3 & 31 \\
\hline 70 & & - & & & & - & 45.5 & 425.0 & 69 \\
\hline 80 & & & & & & - & 51.6 & 552.5 & 90 \\
\hline
\end{tabular}

The highest heat liberation value is observed with compositions is with the addition of $\mathrm{C}-3$, the lowest is with clay-gypsum without additives. As to heat liberation rate, it's the highest with the clay-gypsum binder with the addition of $\mathrm{C}-3$ (the maximum values of the 
rate of heat liberation in the interval $12-15 \mathrm{~min}$ ) on the early stages. The rate of heat liberation of clay-gypsum binder without additives lies within an interval of 14-16 minutes. The rate of heat liberation of the clay-gypsum binder with C-3 and the retarder falls within an interval of 73-76 min.

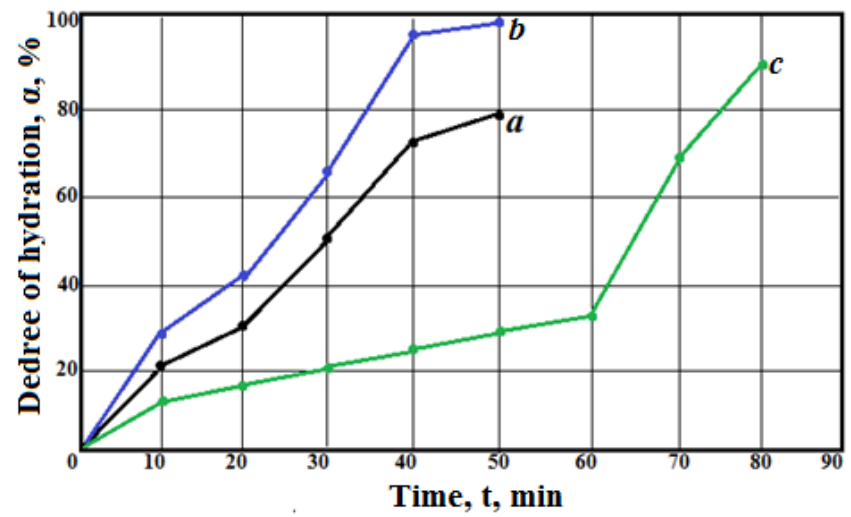

Fig. 5. Degree of hydration of the gypsum binder at dufferent times: a - clay-gypsum binder without additives; $\mathrm{b}$ - clay-gypsum binder with $1 \% \mathrm{C}-3$ additive; $\mathrm{c}$ - clay-gypsum binder with the addition of $1 \% \mathrm{C}-3$ and $0.06 \%$ retarder.

The degree of hydration $(\alpha)$ can be estimated as the ratio of the current heat liberation to the maximum $(\mathrm{qmax}=616.6 \mathrm{~kJ} / \mathrm{kg})$. The results of calculation of the degree of hydration at different times are shown on Fig. 4 and in Table 1. The rate of heat liberation per unit time (kinetics of heat liberation) of the clay-gypsum binder is presented in Table. 2

Table 2. Heat liberation rate. $\mathrm{kJ} /(\mathrm{kg} \cdot \mathrm{s})$ and hydration rate $\% / \mathrm{s}$.

\begin{tabular}{|c|c|c|c|c|c|c|c|c|c|c|c|c|}
\hline \multirow{3}{*}{$\begin{array}{l}\text { Time. } \\
\text { min }\end{array}$} & \multicolumn{12}{|c|}{ Clay-Gypsum Binder } \\
\hline & \multicolumn{4}{|c|}{ Without additives } & \multicolumn{4}{|c|}{ With $1 \% \mathrm{C}-3$ additive } & \multicolumn{4}{|c|}{$\begin{array}{l}\text { With } 1 \% \text { C-3 additive and } 0.06 \\
\% \text { retarder }\end{array}$} \\
\hline & $\begin{array}{l}\text { q. kJ / } \\
\mathrm{kg}\end{array}$ & $\mathrm{dq} / \mathrm{d} \tau$ & $\begin{array}{l}\alpha . \\
\%\end{array}$ & $\begin{array}{l}\mathrm{d} \alpha \\
/ \mathrm{d} \tau\end{array}$ & $\begin{array}{l}\mathrm{q} . \\
\mathrm{kJ} \\
\mathrm{kg}\end{array}$ & $\mathrm{dq} / \mathrm{d} \tau$ & $\alpha . \%$ & $\begin{array}{l}\mathrm{d} \alpha \\
/ \mathrm{d} \tau\end{array}$ & $\begin{array}{ll}\mathrm{q} . & \\
\mathrm{kJ} & / \\
\mathrm{kg}\end{array}$ & $\mathrm{dq} / \mathrm{d} \tau$ & $\alpha . \%$ & $\begin{array}{l}\mathrm{d} \alpha \\
/ \mathrm{d} \tau\end{array}$ \\
\hline 0 & 0 & & & & & & & & 0 & & & \\
\hline 10 & 127.5 & 0.21 & 21 & 0.04 & 170.0 & 0.28 & 28 & 0.05 & 85.0 & 0.15 & 14 & 0.02 \\
\hline 20 & 191.2 & 0.11 & 31 & 0.02 & 255.0 & 0.31 & 41 & 0.02 & 106.3 & 0.04 & 17 & 0.01 \\
\hline 30 & 318.8 & 0.33 & 52 & 0.04 & 403.8 & 0.08 & 66 & 0.04 & 127.5 & 0.04 & 21 & 0.01 \\
\hline 40 & 467.5 & 0.25 & 76 & 0.04 & 595.0 & 0.15 & 97 & 0.05 & 148.8 & 0.02 & 24 & 0.01 \\
\hline 50 & 488.8 & 0.04 & 79 & 0.01 & 616.3 & 0.04 & 100 & 0.01 & 170.0 & 0.04 & 28 & 0.01 \\
\hline 60 & - & - & - & - & - & - & - & - & 191.3 & 0.04 & 31 & 0.01 \\
\hline 70 & - & - & - & - & - & - & - & - & 425.0 & 0.06 & 69 & 0.06 \\
\hline 80 & - & - & - & - & - & - & - & - & 552.5 & 0.21 & 90 & 0.04 \\
\hline
\end{tabular}

\section{Conclusion}

The research shows that the greatest heat liberation has the gypsum-based binder modified by clay with the addition of $\mathrm{C} 3$ superplasticizer. In this case, the degree of hydration of the binder with the addition of $\mathrm{C} 3$ and the retarder is higher than than of the clay-gypsum binder without additives.

When performing internal plaster works hydration terms delay allows laying plaster layers with high quality. The peak of heat liberation during hydration of the clay-gypsum binder with superplasticizer and retarder which occurs at the beginning of the second hour of hardening will promote uniform and high-quality drying of the plaster coating. 


\section{References}

1. B.M. Rumiancev, Textbook (MGSU, Moscow, 2010)

2. V.F. Korovjakov, Increasing the effectiveness of producing and using gypsum materials and products: mat. of the All-Russ. seminar (RAASN, Moscow, 2002)

3. I.V. Bessonov, Increasing the effectiveness of producing and using gypsum materials and products: mat. Of the All-Russ. seminar (Moscow, RAASN, 2002)

4. A.D. Zhukov, V.F. Korovyakov, M.O. Asamatdinov, A.S. Chkunin, G.B. Rumyantsev, Scientific Review 7, 86-90 (2016)

5. B.M. Rumiantcev, A.D. Zhukov, A.V. Orlov, Monograph (MGSU, Moscow, 2014)

6. V.N. Sokov, A.E. Beglyarov, D.U. Zemlyanushnov, D.V. Zhabin, MSUCE Bulletin 12, 309-312 (2011)

7. V.I. Telichenko, D.V. Oreshkin, Ecology of urbanized areas 2, 31-33 (2015)

8. B.M. Rumiantcev, A.D. Zhukov, D.B. Zelenshikov, A.S. Chkunin, K.K. Ivanov, Yu.V. Sazonova, MATEC Web of Conferences, 86 (2016) DOI: http://dx.doi.org/10.1051/matecconf/ 20168604027

9. A.D. Zhukov, Ye.Yu. Bobrova, D.B. Zelenshchikov, R.M. Mustafaev, A.O. Khimich, Advanced Materials. Structures and Mechanical Engineering 1025-1026, 1031-1034 (2014)

10. B.M. Rumiantcev, A.D. Zhukov, E.Y. Bobrova, I.P. Romanova, D.B. Zelenshikov, T.V. Smirnova, MATEC Web of Conferences, 86 (2016) DOI: http://dx.doi.org/10.1051/matecconf/ 20168604036

11. A.D. Zhukov, I.V. Bessonov, A.N. Sapelin, N.V. Naumova, A.S. Chkunin, Italian Science Review 2(11), 155-157 (2014)

12. B.M. Rumjancev, A.D. Zhukov, VolgGASU Internet-herald, 3(23) (2012)

13. B.M. Rumyancev, A.D. Zhukov, E.Y. Bobrova, T.V. Smirnova, Industrial and civil building 1, 32-36 (2015) 